\title{
Relationship between Voriconazole Concentration and Invasive Aspergillosis Treatment Outcome: Efficacy and Safety
}

\author{
Tantasawat $M^{a}$, Puttilerpong $C^{a}$, Panomvana Na Ayudhya ${ }^{a}$, Chantarit $P^{b}$ \\ a Department of Pharmacy Practice, Faculty of Pharmaceutical Science, Chulalongkorn University, Bangkok \\ 10330, Thailand. \\ ${ }^{\mathrm{b}}$ Department of Internal Medicine, Faculty of Medicine, Ramathibodi Hospital, Mahidol University, Bangkok, \\ Thailand.
}

\begin{abstract}
Introduction: This study aimed to determine the association between the voriconazole (VRZ) concentration and clinical outcomes, including both the efficacy and safety in invasive aspergillosis (IA) treatment. Methods: The medical records of adult Thai patients with IA and treated with VRZ at the Ramathibodi Hospital, Thailand, between January 2013 and March 2016 were retrospectively reviewed, and their medical, social, demographic, laboratory data, VRZ dosage regimens and concentrations, and clinical outcome were recorded. The association between the VRZ concentration and clinical outcome was then determined. Results: A total of 81 patients were included in this study. Forty (49.4\%) patients were male, with median age of 56.1 years. Sixty of them had hematologic malignancies. Forty-seven patients were diagnosed with probable IA. Median blood sampling time for VRZ level measurement was $11.5 \mathrm{~h}$ after the last dose administration on day 9. The median duration of treatment and outcome evaluation was 103 days and 73 days, respectively. Overall success and mortality rate were $76.5 \%$ and $14.8 \%$, respectively. In the treatment success group, we found the success rate of around $90 \%$ with VRZ trough concentration $\left(C_{t r}\right)$ of 3-4 $\mathrm{mg} / \mathrm{L}$. Eleven patients developed liver injuries (LI) and the rate of $\mathrm{LI}$ increased significantly with VRZ $\mathrm{C}_{\mathrm{tr}}$ of more than $5 \mathrm{mg} / \mathrm{L}$. Conclusion: We recommend VRZ trough concentration of $3-4 \mathrm{mg} / \mathrm{L}$, as at this range the patients responded better to the treatment than at $>5.0 \mathrm{mg} / \mathrm{L}$ since it was associated with augmented hepatotoxicity.
\end{abstract}

KEYWORDS: voriconazole, invasive aspergillosis, clinical outcome, hepatotoxicity

\section{INTRODUCTION}

Voriconazole (VRZ) is a broad-spectrum triaozole antifungal agent that is currently a drug of choice for invasive aspergillosis (IA). Pharmacodynamic studies using time-kill curve ${ }^{1}$ and murine candidiasis model ${ }^{2}$ suggested an exposure-response relationship. The plasma concentration of VRZ has a large intra- and inter-individual variability with many factors influencing its nonlinear

Corresponding Author:

Dr Chankit Puttilerpong

Department of Pharmacy Practice,

Faculty of Pharmaceutical Science,

Chulalongkorn University,

Bangkok 10330, Thailand.

No. Tel. : (66-2) 218-8403

E-mail : chankit.p@chula.ac.th pharmacokinetics, such as the patient's age, liver disease, drug-drug interactions and polymorphisms of the gene encoding the metabolizing enzymes (mainly CYP2C19). ${ }^{3-6}$ In clinical practice, the association between a low VRZ concentration and poor clinical outcome has been reported ${ }^{7,8}$, but this relationship is still equivocal and inconsistent. Some clinical studies have not found an association between the treatment outcome and VRZ drug level. ${ }^{5-9}$ Other than the VRZ concentration, many other factors influence the treatment outcome, including the patient's immune status, age, comorbidities and removal of infected tissue. ${ }^{10,11}$ Adverse effects associated with VRZ include hepatotoxicity or elevated serum levels of hepatic enzymes, neurotoxicity, which may present with hallucination or visual disturbance, and rash. 
Disagreement on the relationship between the adverse events and VRZ concentration has also been reported. ${ }^{5,12-15}$ This study was performed to clarify the association between the VRZ concentration and clinical outcomes (both efficacy and safety) to address the necessity of therapeutic drug monitoring (TDM).

\section{Methods}

\section{Patient enrolment and data collection}

Thai adult (age $\geq 18 \mathrm{y}$ ) patients with IA who had been treated with VRZ at Ramathibodi Hospital, Thailand between January 2013 and March 2016 were eligible for inclusion. Patients' medical records were reviewed and patient-specific characteristics were retrospectively collected, including gender, age, body weight, height, underlying disease(s), diagnose of IA, laboratory data and CYP2C19 phenotype. The IA was classified in accordance with the European Organization for Research and Treatment of Cancer and Mycoses Study Group (EORTC/MSG) criteria, which were proven, probable and possible invasive fungal infections. ${ }^{2}$ The laboratory data included the serum creatinine $(\mathrm{SCr})$, creatinine clearance $(\mathrm{ClCr})$, aspartate aminotransferase (AST), alanine aminotransferase (ALT), alkaline phosphatase (ALP), Y-glutamyl transpeptidase (GGT), total bilirubin (TB), direct bilirubin (DB) and albumin (Alb) levels were collected. Estimation of $\mathrm{ClCr}$ was performed using the Cockcroft-Gault formula. The VRZ dosage regimen, administration time, blood sampling time, VRZ trough concentration $\left(C_{t r}\right)$, duration of VRZ treatment and clinical outcomes were recorded. Patients were excluded if: (a) they had severe hepatic diseases, as defined by the Common Terminology Criteria for Adverse Events (CTCAE) version 4.0 of grade $\geq 4$, or (b) they were pregnant.

Voriconazole concentrations were analyzed at the Ramathibodi Hospital, Thailand. In addition, the validated liquid chromatography mass spectrometry (LC-MS/MS) assay was utilized to measure the VRZ concentrations. For plasma VRZ concentrations to be included in the analyses, levels were required to be taken at steady state and considered to be the trough level. Moreover, VRZ was considered to be at steady state after $24 \mathrm{~h}$ of administration following two loading doses or after 5 days without loading doses and blood samples were drawn before the next dose. ${ }^{3}$ The time after the last administration dose to blood sampling (TAD) vary depended on the meal time. In this study, voriconazole concentrations with TAD ranging from 9-14 hours were considered to be the $C_{t r}$. Voriconazole concentrations were measured by validated method using LC/MS/MS performed by pharmacogenomics laboratory, Faculty of Medicine, Ramathibodi Hospital, Thailand. Blood samples from each patient were collected into EDTA tubes. Plasma was collected by centrifugation at $3000 \mathrm{rpm}$ for $15 \mathrm{~min}$. Standard solutions were prepared at eight concentrations; 10,000, 5000, 2500, 1200, 800, 400, 100 and $50 \mathrm{ng} / \mathrm{ml}$, respectively. Fluconazole was used as an internal standard (IS). Protein in the samples $(100 \mathrm{ml})$ were precipitated by $100 \%$ acetonitrite $(200 \mathrm{ml})$ and vortex -mixed (60 s) and centrifuged (MIKRO 200) at 15,000 $\mathrm{rpm}$ for $5 \mathrm{~min}$, then vacuum dried at $50{ }^{\circ} \mathrm{C}$ for $1 \mathrm{~h}$ and $50 \mathrm{~min}$. $0.1 \%$ formic acid in $10 \mathrm{mM}$ ammonium acetate-acetronitrile $(50: 50) \quad(100 \mathrm{ml})$ was added before further centrifugation at a speed of 15,000 rpm for $5 \mathrm{~min}$. The supernatant was analyzed with LC/MS/MS Model API 3200. The Linear Regression Equation for measurement of voriconazole in the bloodstream was calculated from an average of three samples from each patient: $\mathrm{y}=0.01334 \mathrm{X}+3.1, \mathrm{r}=$ 0.9994 .

Clinical outcomes were assessed for both the efficacy and safety. Efficacy was assessed by using the clinical and radiological criteria at any time after treatment that a repeated computerized tomography (CT) scan was performed and the outcomes were categorized as success and failure (table I).

Hepatotoxicity was defined as (i) symptomatic with serum ALT levels of more than three-fold the upper normal limit (UNL), or total bilirubin levels of more than two-fold the UNL or, (ii) asymptomatic with serum ALT levels of more than five-fold the upper normal limit (UNL), or total bilirubin levels of more than three-fold the UNL. ${ }^{8}$

This study was performed in accordance with the Declaration of Helsinki, 1996 good clinical practice, and the study protocol was approved by the Ethics Committee of Ramathibodi Hospital, Thailand (Protocol number 07-57-21).

\section{Statistical analysis}

Statistical analysis was performed using the SPSS version 21 (SPSS Inc., Chicago, IL, USA) software. 
Table I: Definitions of clinical outcomes

\begin{tabular}{|c|c|}
\hline Clinical outcomes & Definition \\
\hline & $\begin{array}{l}\text { (i) complete response: survival within the pre-specified period of observation, } \\
\text { and resolution of all attributable symptoms and signs of infection and } \\
\text { radiological abnormalities, and mycological evidence of eradication of } \\
\text { infection; }\end{array}$ \\
\hline Success & $\begin{array}{l}\text { (ii) partial response: survival within the pre-specified period of observation, } \\
\text { and improvement in attributable symptoms and signs of infection and } \\
\text { radiological abnormalities, and evidence of sterilization of cultures or } \\
\text { reduction of fungal burden assessed by a quantitative and validated laboratory } \\
\text { marker }\end{array}$ \\
\hline \multirow{3}{*}{ Failure } & $\begin{array}{l}\text { (i) stable response: survival within the pre-specified period of observation and } \\
\text { minor or no improvement in fungal disease, but no evidence of progression, } \\
\text { based on a composite of clinical, radiological, and mycological criteria; }\end{array}$ \\
\hline & $\begin{array}{l}\text { (ii) progression of fungal disease: evidence of progressive fungal disease based } \\
\text { on a composite of clinical, radiological, and mycological criteria }\end{array}$ \\
\hline & $\begin{array}{l}\text { (iii) death: death during the pre-specified period of evaluation regardless of } \\
\text { attribution. }\end{array}$ \\
\hline $\begin{array}{l}\text { Non-evaluable or } \\
\text { indeterminate }\end{array}$ & $\begin{array}{l}\text { inability to assess global response. Potential reasons included inadequate } \\
\text { diagnostic evaluation, conflicting clinical, radiographic, or mycological data, or } \\
\text { presence of other factors such as an unrelated infection or relapse of } \\
\text { malignancy that confound assessment of response to antifungal therapy }\end{array}$ \\
\hline
\end{tabular}

Continuous data are presented as medians (interquartile range $[\mathrm{IQR}]$ ) and categorical data as proportions. A $\mathrm{p}$-value of less than 0.05 was considered as statistically significant.

\section{RESULTS}

A total of 81 patients were included in this study. $49.4 \%$ were male. The median age of all patients was 56.1 years (range, 18.1-86.5 years). The median weight at the start of the VRZ therapy was $56.1 \mathrm{~kg}$ (range, 38.8-82.0 kg). Sixty (74.1\%) patients had hematologic malignancies. $58.0 \%$ were diagnosed with probable IA with the most frequent source of infection was the lung $(\mathrm{N}=62,82.7 \%)$. Considering the baseline liver function tests (LFTs), our patients had median ALP and GGT serum levels above the ULN values and a median albumin level lower than the normal value. Moreover, their median hemoglobin, hematocrit and platelet counts were lower than the normal ranges, while other laboratory tests were in the normal range. According to their CYP2C19 phenotype, 34 (47.9\%) patients were extensive metabolizers, 31 (43.6\%) patients were intermediate metabolizers and only 6 (8.4\%) patients were poor metabolizers (Table II).
Regarding voriconazole administration, most of the patients $(89.0 \%)$ received VRZ as oral dose with median loading dose of $12 \mathrm{mg} / \mathrm{kg} /$ day followed by median maintenance dose of $8 \mathrm{mg} / \mathrm{kg} /$ day. After VRZ initiation, blood samples were drawn for VRZ concentration measurement with a median of $11.5 \mathrm{~h}$ after the last dose administration on day 9 (range 3$164 \mathrm{~d}$ ). For three patients with blood sampling before day 5, they received VRZ loading dose, therefore, steady state was assumed after $24 \mathrm{~h}$. The median initial, second, and third VRZ $C_{t r}$ were $2.17 \mathrm{mg} / \mathrm{L}$, $2.40 \mathrm{mg} / \mathrm{L}$, and $2.34 \mathrm{mg} / \mathrm{L}$, respectively and were not significantly different and were in the present recommended therapeutic range. The median duration of treatment was 103 days with median outcome evaluation on day 73 .

The overall success rate in this study was $76.5 \%$. Among the 19 patients with failure to response, 12 patients died due to any cause (mortality rate = $14.8 \%)$. After patients with possible IA $(\mathrm{N}=64)$ were excluded, demographic data of the remaining patients was not different from all patients and the treatment outcome was also comparable with the overall success and mortality rate of $73.4 \%$ and $17.2 \%$, respectively (Table III). 


\begin{tabular}{|c|c|}
\hline Characteristics & All patients $(\mathrm{N}=81)$ \\
\hline Age - median, years (range) & $54.6(18.1-86.5)$ \\
\hline Gender, male (\%) & $40(49.4)$ \\
\hline female $(\%)$ & $41(50.6)$ \\
\hline Weight - median, kg (range) & $56.1(38.8-82.0)$ \\
\hline \multicolumn{2}{|l|}{ Underlying condition - number (\%) } \\
\hline Hematologic malignancy & $60(74.1)$ \\
\hline Solid tumor & $4(4.9)$ \\
\hline Immunosuppressive Therapy & $9(11.1)$ \\
\hline HIV/AIDS & $2(2.5)$ \\
\hline Other condition & $2(2.5)$ \\
\hline None & $4(4.9)$ \\
\hline \multicolumn{2}{|l|}{ Fungal Infection - number (\%) } \\
\hline Proven & $17(21.0)$ \\
\hline Probable & $47(58.0)$ \\
\hline Possible & $17(21.0)$ \\
\hline \multicolumn{2}{|l|}{ Source of infection - number (\%) } \\
\hline Lung & $67(82.7)$ \\
\hline Sinus & $13(16.0)$ \\
\hline Disseminated & $1(1.2)$ \\
\hline Baseline laboratory tests (normal range) ${ }^{a}$ & Median (IQR) \\
\hline $\mathrm{S}_{\mathrm{Cr}}(0.4-1.2 \mathrm{mg} / \mathrm{dL})$ & $0.91(0.55)$ \\
\hline $\mathrm{Cl}_{\mathrm{Cr}}(\mathrm{mL} / \mathrm{min})$ & $70.0(45.8)$ \\
\hline AST (15-37 U/L) & $35(28)$ \\
\hline $\operatorname{ALT}(30-65 \mathrm{U} / \mathrm{L})$ & $43(44)$ \\
\hline $\operatorname{ALP}(50-136 \mathrm{U} / \mathrm{L})$ & $160(187)$ \\
\hline GGT (male: 15-85 U/L, female 5-55 U/L) & 319 (418), 258 (337) \\
\hline $\mathrm{TB}(0.2-1.2 \mathrm{mg} / \mathrm{dL})$ & $0.7(0.6)$ \\
\hline Baseline laboratory tests (normal range) ${ }^{a}$ & Median (IQR) \\
\hline DB $(0.0-0.3 \mathrm{mg} / \mathrm{dL})$ & $0.3(0.4)$ \\
\hline Albumin $(35-50 \mathrm{~g} / \mathrm{L})$ & $28.3(11.3)$ \\
\hline WBC $\left(4,000-10,700\right.$ cells $\left./ \mathrm{cm}^{3}\right)$ & $5,745(6,690)$ \\
\hline$\%$ N (40\%-74\%) & $70(33)$ \\
\hline ANC $\left(1,500-8,000\right.$ cells $\left./ \mathrm{mm}^{3}\right)$ & $3,781(4,917)$ \\
\hline $\begin{array}{l}\mathrm{Hb} \text { (male: } 14.0-17.5 \mathrm{~g} / \mathrm{dL} \\
\text { female: } 12.0-16.0 \mathrm{~g} / \mathrm{dL} \text { ) }\end{array}$ & $\begin{array}{l}10.2(2.0) \\
9.4(1.9)\end{array}$ \\
\hline $\begin{array}{l}\text { Hct (male: } 40 \%-54 \% \\
\text { female: } 36 \%-48 \% \text { ) }\end{array}$ & $\begin{array}{l}30.1(6.2) \\
29.2(6.0)\end{array}$ \\
\hline Plt $\left(140-450 \times 10^{3} / \mathrm{mm}^{3}\right)$ & $129(118)$ \\
\hline \multicolumn{2}{|c|}{ CYP2C19 phenotypes and genotypes $(\mathrm{N}=71)$ - number $(\%)$} \\
\hline \multicolumn{2}{|c|}{$E M(N=34,47.9 \%)$} \\
\hline$* 1 / * 1$ & $34(47.9)$ \\
\hline \multicolumn{2}{|l|}{ IM $(\mathrm{N}=31,43.6 \%)$} \\
\hline$* 1 / * 2$ & $26(36.6)$ \\
\hline$* 1 / * 3$ & $5(7.0)$ \\
\hline \multicolumn{2}{|l|}{$\mathrm{PM}(\mathrm{N}=6,8.4 \%)$} \\
\hline${ }^{*} 2 / * 2$ & $4(5.6)$ \\
\hline$* 2 / * 3$ & $1(1.4)$ \\
\hline$* 3 / * 3$ & $1(1.4)$ \\
\hline
\end{tabular}

${ }^{a}$ Reference data from clinical pathology laboratory, Ramathibodi hospital, Bangkok, Thailand. 
Con't

Abbreviation: Alb: albumin; ALP: alkaline phosphatase; ALT: alanine aminotransferase; ANC: absolute neutrophil count; AST: aspartate aminotransferase; $\mathrm{Cl}_{\mathrm{cr}}$ : creatinine clearance; DB: direct bilirubin; EM: extensive metabolizer; GGT: g-glutamyl transpeptidase; Hb: hemoglobin; Hct: hematocrit; IM: intermediate metabolizer; Plt: platelet; PM: poor metabolizer; $\mathrm{S}_{\mathrm{Cr}}$ : serum creatinine; TB: total bilirubin.

Table III VRZ dosage regimen and treatment outcome of individuals eligible for clinical outcome assessment $(\mathrm{N}=81)$

VRZ dosage regimen, blood sampling time, and VRZ level

Route of administration - number (\%)

Switch from intravenous to oral

$17(21.0)$

Oral

$64(89.0)$

Voriconazole daily dosing - median, $\mathrm{mg} / \mathrm{kg} /$ day (range)

Loading dose (oral or intravenous)

12

Maintenance dose

No. of samples per patient - median, number (range)

Days from the start of therapy to sampling - median, days (range)

$9(3-164)$

Hours between last dose and trough drug level - median, hours (range)

$11.5(9-14)$

Voriconazole level - median, $\mathrm{mg} / \mathrm{L}$ (range)

Initial level $(\mathrm{N}=81)$

$2.17(0.11-12.40)$

Second level $(\mathrm{N}=67)$

$2.40(0.52-9.71)$

Third level $(\mathrm{N}=55)$

$2.34(0.17-10.17)$

Duration of therapy - median, days (range)

$103(8-655)$

Duration of outcome evaluation - median, days (range)

$73(7-341)$

Treatment outcome - number (\%)

Success

$62(76.5)$

Complete response

$13(16.0)$

Partial response

49 (60.5)

Failure

Stable response

Progression of fungal disease

Dead due to any causes

$12(14.8)$

Considering the effect of site of infection on success rate and duration of treatment, when VRZ $\mathrm{C}_{\mathrm{tr}}$ was maintained in similar therapeutic range, patients with aspergillus lung infection responded better with a higher success rate $(p=0.0016)$ and required a shorter duration of treatment compared to sinus infection (Table IV).

Nineteen patients failed to respond to voriconazole treatment. Eleven patients were male and three patients aged more than 65 years. Most of them $(17 / 19$ cases) were diagnosed as having probable or proven IA. Of all, twelve patients died and among them, invasive aspergillosis was determined as the cause of death in 4 cases.

Regarding the correlation between VRZ $C_{t r}$ and treatment success, we found the success rate of more than $90 \%$ with VRZ $C_{t r}$ of $>3$ to $4 \mathrm{mg} / \mathrm{L}$ and more than $95 \%$ with VRZ $C_{\text {tr }}$ of $>4$ to $5 \mathrm{mg} / \mathrm{L}$. This finding indicated that the optimal VRZ $C_{t r}$ for IA treatment success should be between 3 to $4 \mathrm{mg} / \mathrm{L}$, while for level of $4-5 \mathrm{mg} / \mathrm{L}$, the success rate increased only by $4.9 \%$ (Table $\mathrm{V}$ ). 
Table IV Comparison of VRZ level, treatment outcome, and duration of treatment between Aspergillus lung and sinus infection $(\mathrm{N}=80)$

\begin{tabular}{|c|c|c|c|}
\hline & Lung $(\mathrm{N}=67)^{\mathrm{a}}$ & Sinus $(N=13)^{a}$ & $p$-value \\
\hline \multicolumn{4}{|l|}{ VRZ level (mg/L) } \\
\hline median \pm IQR (range) & $2.74 \pm 2.08(0.56-8.20)$ & $2.51 \pm 0.96(1.33-4.13)$ & 0.917 \\
\hline Success treatment, number (\%) & $58(86.6)$ & $10(76.9)$ & $0.0016^{* *}$ \\
\hline \multicolumn{4}{|l|}{ Duration of treatment (d) } \\
\hline median \pm IQR (range) & $104 \pm 99(33-363)$ & $282 \pm 557(46-655)$ & $0.013^{*}$ \\
\hline
\end{tabular}

Hepatotoxicity or drug-induced liver injury (DILI) was the only adverse effect observed during this study. Hepatotoxicity developed in 11 (13.6\%) patients. Seven $(63.6 \%)$ patients were male, only one patient aged over 65 years, and $4(40 \%)$ were CYP2C $19 * 1 / * 2$ genotype while the remaining were CYP2C19 $* 1 / * 1$ genotype. Three patients had chronic HBV or HCV infection and one patient had alcoholic cirrhosis of the liver. The onset of DILI was from 5 to 326 days after VRZ initiation. The dose of VRZ that caused DILI was from $400 \mathrm{mg}$ to $600 \mathrm{mg}$ daily with VRZ $C_{\text {tr }}$ of $0.63-10.17 \mathrm{mg} / \mathrm{L}$.

The last VRZ $C_{\text {tr }}$ prior to the onset of DILI was 2.50$12.30 \mathrm{mg} / \mathrm{L}$ (from day 5-97 before the onset of DILI). DILI did not correlate with the treatment response because 8/11 patients who developed DILI had successful treatment.

Table $\mathbf{V}$ Number of patients with successful response stratified by voriconazole trough concentrations $(\mathrm{N}=62)$

\begin{tabular}{cccc}
\hline VRZ $C_{\text {trough }}$ & Number of patients & \% success & Cumulative \% success \\
\hline$<1$ & 6 & 9.7 & 9.7 \\
$\geq 1-2$ & 19 & 30.6 & 40.3 \\
$>2-3$ & 16 & 25.8 & 66.1 \\
$>3-4$ & 15 & 24.2 & 90.3 \\
$>4-5$ & 3 & 4.9 & 95.2 \\
$>5$ & 3 & 4.8 & 100.0 \\
\hline
\end{tabular}

Level of patients with successful response, median \pm IQR $($ range $)=2.48 \pm 1.75(0.56-8.20)$

To verify the relationship between VRZ $\mathrm{C}_{\mathrm{tr}}$ and DILI, patients were stratified by VRZ $C_{t r}$. We found that the rate of DILI increased sharply with VRZ $C_{t r}$ of more than $5 \mathrm{mg} / \mathrm{L}$ for both VRZ $\mathrm{C}_{\mathrm{tr}}$ at the onset of DILI and the last VRZ $C_{\text {tr }}$ prior to the onset of DILI (Table Vl).

Table VI Number of patient with DILI stratified by voriconazole trough concentrations $(\mathrm{N}=11)$

\begin{tabular}{cccc}
\hline \multicolumn{2}{c}{ DILI $(\mathrm{N}=11)$} & \multicolumn{2}{c}{ DILI-1 $(\mathrm{N}=9)$} \\
\hline VRZ $C_{\mathrm{tr}}$ & Number of patients (\%) & VRZ $\mathrm{Ctr}_{\mathrm{tr}}$ & Number of patients (\%) \\
\hline$<1$ & $1(9.1)$ & $<1$ & 0 \\
$\geq 1-2$ & $1(9.1)$ & $\geq 1-2$ & 0 \\
$>2-3$ & $1(9.1)$ & $>2-3$ & $2(22.2)$ \\
$>3-4$ & $1(9.1)$ & $>3-4$ & $1(11.1)$ \\
$>4-5$ & $2(18.2)$ & $>4-5$ & $2(22.2)$ \\
$>5$ & $5(45.5)$ & $>5$ & $4(44.4)$ \\
\hline
\end{tabular}

DILI; drug-induced liver injury, DILI VRZ $C_{t r}$ were the level between 0-14 d before DILI occur, DILI-1; indicated the last investigation prior to development of DILI- 


\section{DISCUSSION}

The overall success rate in the present study $(76.5 \%)$ was higher than that reported by others ${ }^{13,14 \text {, }}$ ${ }^{16}$, which was possibly due to the restricted VRZ use, thus less resistance strain development in our setting. Although the minimum inhibitory concentration (MIC) of VRZ for Aspergillus spp. was only determined in two cases $(<0.1 \mathrm{mg} / \mathrm{L}$ in both cases), these were lower than those reported in another study ${ }^{17}$ whereby more than $80 \%$ of the most frequent Aspergillus spp. (A. fumigatus (2778 isolates), A. flavus (589 isolates), A. terrueus (462 isolates) and $A$. niger (479 isolates)) had a VRZ MIC of $>0.125 \mathrm{mg} / \mathrm{L}$ and more than $50 \%$ of them had a VRZ MIC of $>0.25 \mathrm{mg} / \mathrm{L} .{ }^{17}$ Therefore, for all our patients who had a median VRZ concentration of more than $0.5 \mathrm{mg} / \mathrm{L}$, the drug levels were severalfold higher than the MIC value which were sufficient to control the pathogen, leading to the higher success rate.

The blood sampling time varied over the diverse range of 9 to $16 \mathrm{~h}$ because there was no definitive VRZ administration protocol in our institution, especially for oral administration. Oral VRZ should be administered on an empty stomach which was 1 $\mathrm{h}$ before or $2 \mathrm{~h}$ after a meal, and so the VRZ administration times were adjusted to the patients' meal time. For example, breakfast and dinner time in our setting were $7 \mathrm{AM}$ and $5 \mathrm{PM}$ so the drug administration times were $6 \mathrm{AM}$ and $4 \mathrm{PM}$. For VRZ $C_{\text {tr }}$ monitoring, blood samples were collected around 30 min before the administration of the next VRZ dose, and so the blood sampling time depended on the drug administration time. This could explain the high variation in VRZ concentrations.

This study found the association between VRZ $C_{t r}$ and treatment success, similar to Dolton et al who reported a significant relationship between treatment failure and VRZ concentrations of less than $1.7 \mathrm{mg} / \mathrm{L}$ in patients with IFIs ${ }^{18}$, while another study concluded that the IFI-related mortality correlated with an initial VRZ $C_{t r}$ of $\leq 0.35 \mathrm{mg} / \mathrm{L}$ and successful outcomes were more likely among patients with a median VRZ $C_{t r}$ of more than 2.2 $\mathrm{mg} / \mathrm{L} .{ }^{13}$ Nevertheless, patients with a median VRZ $C_{t r}$ of $2.38 \mathrm{mg} / \mathrm{L}$ were more likely to face severe adverse effects than those with a median VRZ $C_{t r}$ of $1.30 \mathrm{mg} / \mathrm{L}$.
In addition, the VRZ prophylaxis was found to be most effective at a VRZ $C_{\text {tr }}$ of more than $1.5 \mathrm{mg} / \mathrm{L}$ in lung transplant recipients. ${ }^{19}$

Regarding the adverse effect of VRZ, in this study there was an increased rate of hepatotoxicity with VRZ $C_{\text {tr }}$ of more than $5 \mathrm{mg} / \mathrm{L}$ comparable to another research where Asian patients whose VRZ $C_{\text {tr }}$ was $<5$ $\mathrm{mg} / \mathrm{L}$, exhibited a lower rate of hepatotoxicity ${ }^{20}$ and a higher rate of neurotoxicity was found when the VRZ $C_{\text {tr }}$ was more than $5 \mathrm{mg} / \mathrm{L}^{18}$ The median VRZ concentrations were significantly higher in patients with severe adverse events $(6.32 \mathrm{mg} / \mathrm{L}$ vs. $2.15 \mathrm{mg} /$ L). ${ }^{12}$ In addition, Dolton et al also reported a relationship between VRZ $C_{t r}$ of $4-6 \mathrm{mg} / \mathrm{L}$ and hepatotoxicity or neurotoxicity. ${ }^{21}$ On the other hand, some studies could not elucidate the relationship between VRZ concentrations and adverse events. ${ }^{5,9}$ In addition, this study's results indicated that DILI were associated with both VRZ $C_{t r}$ at the time of DILI and VRZ $C_{\text {tr }}$ prior to DILI presentation. This finding concurs with a study by Suzuki et. al who reported that sustained high trough concentration of voriconazole may increase the risk of hepatotoxicity, and a decreased trough concentration of less than 4 $\mathrm{mg} / \mathrm{L}$, by dose adjustment after the initial TDM, may reduce the incidence of hepatotoxicity. ${ }^{14}$

The limitations of this study include its retrospective design. In addition, since there were only six members of the PM group included in this study, we could not calculate the recommended dose for each phenotypic group (EM, IM and PM), which might be more optimal for each individual as compared to Barbarino et $\mathrm{al}^{22}$ and Lamoureux et $\mathrm{al}^{23}$ who recommended genotype-directed dosing of VRZ. In addition, over-exposure of VRZ in patients with a CYP2C19 genotypes associated with poor or intermediate metabolism ${ }^{24}$ and lower steady-state VRZ $C_{t r}$ with higher prevalence of subtherapeutic in rapid or ultrarapid metabolizer ${ }^{25}$ have been reported. Furthermore, the time after the last administration dose to the time of blood sampling varied depending on meal time, ranging from 9 to 14 $\mathrm{h}$, the VRZ $\mathrm{C}_{\mathrm{tr}}$ thus had high variation. This scenario may actually reflect the real-world practice. Regarding time to steady state, VRZ exerts nonlinear pharmacokinetics, so the time to reach steady state depends on its half-life. Difference in dose and CYP2C19 phenotype could alter VRZ half-life. Collection of blood samples for VRZ monitoring at 
steady state thus should not be the same time for each individual while those were performed on day 7 after VRZ initiation in our setting. We recommended monitoring two consecutive $C_{t r}$ for verification of steady state. Further prospective studies with larger number of patients with each CYP2C19 phenotype are needed. Furthermore, because the MICs of Aspergillus spp. were identified only in two cases in this study, the correlation between MIC or $\mathrm{C}_{\mathrm{tr}} / \mathrm{MIC}$ and clinical outcome could not be determined.

In conclusion, it is advisable to initiate the VRZ treatment with the recommended doses followed by therapeutic drug monitoring to maintain the VRZ $\mathrm{C}_{\mathrm{tr}}$ of $3-4 \mathrm{mg} / \mathrm{L}$ to successfully treat the IA and to avoid hepatotoxicity.

\section{FUNDING}

This study was funded by National Science and Technology Development Agency (NSTDA), Thailand.

\section{REFERENCES}

1. Kontoyiannis DP, Patterson TF. Diagnosis and treatment of invasive fungal infections in the cancer patient: recent progress and ongoing questions. Clin Infect Dis. 2014;59(Suppl 5):S356-S9.

2. De Pauw B, Walsh TJ, Donnelly JP, Stevens DA, Edwards JE, Calandra T, et al. Revised definitions of invasive fungal disease from the European organization for research and treatment of cancer/invasive fungal infections cooperative group and the national institute of allergy and infectious diseases mycoses study group (EORTC/MSG) consensus group. Clinical Infect Dis. 2008;46:1813-21.

3. Theuretzbacher U, Ihle F, Derendorf $\mathrm{H}$. Pharmacokinetic/pharmacodynamic profile of “voriconazole" Clin Pharmacokinet. 2006;45 (7):649-63R.

4. Lee S, Kim BH, Nam WS, Yoon SH, Cho JY, Shin SG, et al. Effect of CYP2C19 polymorphism on the pharmacokinetics of voriconazole after single and multiple doses in healthy volunteers. J Clin Pharmacol. 2012;52(2):195203.

5. Racil Z, Winterova J, Kouba M, Zak P, Malaskova L, Buresova L, et al. Monitoring trough voriconazole plasma concentrations in haematological patients: real life multicentre experience. Mycoses. 2012;55(6):483-92.

6. Weiss J, Ten Hoevel MM, Burhenne J, WalterSack I, Hoffmann MM, Rengelshausen J, et al. CYP2C19 genotype is a major factor contributing to the highly variable pharmacokinetics of voriconazole. J Clin Pharmacol. 2009;49(2):196-204.

7. Denning DW, Ribaud P, Milpied N, Caillot D, Herbrecht R, Thiel E, et al. Efficacy and safety of voriconazole in the treatment of acute invasive aspergillosis. Clinical Infect Dis. 2002;34:563-71.

8. Pascual A, Calandra T, Bolay S, Buclin T, Bille $\mathrm{J}$, Marchetti $\mathrm{O}$. Voriconazole therapeutic drug monitoring in patients with invasive mycoses improves efficacy and safety outcomes. Clin Infect Dis. 2008;46(2):201-11.

9. Chu HY, Jain R, Xie H, Pottinger P, Fredricks DN. Voriconazole therapeutic drug monitoring: retrospective cohort study of the relationship to clinical outcomes and adverse events. BMC Infect Dis. 2013;13:105.

10. Johnson HJ, Han K, Capitano B, Blisard D, Husain S, Linden PK, et al. Voriconazole pharmacokinetics in liver transplant recipients. Antimicrob Agents Chemother. 2010;54(2):852-9.

11. Hassan A, Burhenne J, Riedel KD, Weiss J, Mikus G, Haefeli WE, et al. Modulators of very low voriconazole concentrations in routine therapeutic drug monitoring. Ther Drug Monit. 2011;33:86-93. 2011;33:86-93.

12. Kim SH, Yim DS, Choi SM, Kwon JC, Han S, Lee DG, et al. Voriconazole-related severe adverse events: clinical application of therapeutic drug monitoring in Korean patients. Int J Infect Dis. 2011;15(11):e753-8.

13. Miyakis S, J. van Hal S, Ray J, Marriott D. Voriconazole concentrations and outcome of invasive fungal infections. Clin Microbiol Infect 2010;16:927-33.

14. Chu HY, Jain R, Xie H, Pottinger P, Fredricks DN. Voriconazole therapeutic drug monitoring: retrospective cohort study of the relationship to clinical outcomes and adverse events. BMC Infect Dis. 2013;13(105).

15. Suzuki Y, Tokimatsu I, Sato Y, Kawasaki K, Sato Y, Goto T, et al. Association of sustained high plasma trough concentration of voriconazole with the incidence of 
hepatotoxicity. Clin Chim Acta. 2013;424:11922.

16. Scott LJ, Simpson D. Voriconazole: a review of its use in the management of invasive fungal infections. Drugs. 2007;67(2):269-98.

17. Xu G, Zhu L, Ge T, Liao S, Li N, Qi F. Pharmacokinetic/pharmacodynamic analysis of voriconazole against Candida spp. and Aspergillus spp. in children, adolescents and adults by Monte Carlo simulation. Int J Antimicrob Agents. 2016;47(6):439-45.

18. Dolton MJ, Ray JE, Chen SC, Ng K, Pont LG, McLachlan AJ. Multicenter study of voriconazole pharmacokinetics and therapeutic drug monitoring. Antimicrob Agents Chemother. 2012;56(9):4793-9.

19. Mitsani D, Nguyen MH, Shields RK, Toyoda $Y$, Kwak EJ, Silveira FP, et al. Prospective, observational study of voriconazole therapeutic drug monitoring among lung transplant recipients receiving prophylaxis: factors impacting levels of and associations between serum troughs, efficacy, and toxicity. Antimicrob Agents Chemother. 2012;56(5):2371-7.

20. Chen K, Zhang X, Ke X, Du G, Yang K, Zhai S. Individualized medication of voriconazole: a practice guideline of the division of therapeutic drug monitoring, Chinese pharmacological society. Ther Drug Monit. 2018;40(6):663-74.

21. Dolton MJ, McLachlan AJ. Voriconazole pharmacokinetics and exposure-response relationships: assessing the links between exposure, efficacy and toxicity. Int J Antimicrob Agents. 2014;44(3):183-93.

22. Barbarino JM, Obeng AO, Klein TE, Altman RB. PharmGKB summary: voriconazole pathway, pharmacokinetics. Pharmacogenet Genomics. 2017;27(5):201-9.

23. Lamoureux F, Duflot T, Woillard JB, Metsu D, Pereira $T$, Compagnon $P$, et al. Impact of CYP2C19 genetic polymorphisms on voriconazole dosing and exposure in adult patients with invasive fungal infections. Int J Antimicrob Agents. 2016;47(2):124-31.

24. Miao Q, Tang JT, van Gelder T, Li YM, Bai YJ, Zou YG, et al. Correlation of CYP2C19 genotype with plasma voriconazole exposure in South-western Chinese Han patients with invasive fungal infections. Medicine. 2019;98:3(e14137).
25. Hamadeh IS, Klinker KP, Borgert SJ, Richards Al, Li W, Mangal N, et al. Impact of the CYP2C19 genotype on voriconazole exposure in adults with invasive fungal infections. Pharmacogenet Genomics. 2017;27(5):190-6. 